\title{
Concerns and Trade-offs in Information Technology Acceptance: The Balance between the Requirement for Privacy and the Desire for Safety
}

\author{
Ehrari, Humira; Ulrich, Frank; Andersen, Henning Boje
}

Published in:

Communications of the Association for Information Systems

Link to article, DOI:

10.17705/1CAIS.04711

Publication date:

2020

Document Version

Peer reviewed version

Link back to DTU Orbit

Citation (APA):

Ehrari, H., Ulrich, F., \& Andersen, H. B. (2020). Concerns and Trade-offs in Information Technology Acceptance: The Balance between the Requirement for Privacy and the Desire for Safety. Communications of the Association for Information Systems, 47. https://doi.org/10.17705/1CAIS.04711

\section{General rights}

Copyright and moral rights for the publications made accessible in the public portal are retained by the authors and/or other copyright owners and it is a condition of accessing publications that users recognise and abide by the legal requirements associated with these rights.

- Users may download and print one copy of any publication from the public portal for the purpose of private study or research.

- You may not further distribute the material or use it for any profit-making activity or commercial gain

- You may freely distribute the URL identifying the publication in the public portal 


\title{
Concerns and Trade-offs in Information Technology Acceptance: The Balance between the Requirement for Privacy and the Desire for Safety ${ }^{1}$
}

Humira Ehrari (1), Frank Ulrich (2) and Henning Boje Andersen (3)

(1) homiraaa@hotmail.com; Technical University of Denmark, Management Department, Kgs. Lyngby, Denmark

(2) mail@frankulrich.org; Technical University of Denmark, Department Technology and Innovation

(3) hebq@dtu.dk; Technical University of Denmark, Management Department, Kgs. Lyngby, Denmark

\begin{abstract}
:
In this paper, we propose a new motivation model by bridging self-determination theory (SDT) with the unified theory of acceptance and use of technology (UTAUT). Using an explorative approach, we study how human motivational determinants influence the trade-off between safety and privacy in technology acceptance. We take the Scandinavian healthcare context as our empirical outset and explore how older Danish adults perceive sensor-based e-health monitor technology that monitors their health status. Danish municipalities have begun to use these technologies to identify early warning signs and, thereby, improve the quality of care and life by making people more self-reliant and reducing unnecessary hospitalization. However, one needs to consider ethical issues concerning privacy versus safety when implementing these technologies. After monitoring 21 respondents (mean age: 85 ) living independently at home over nine weeks, we interviewed them about their concerns regarding privacy and safety. We found that the respondents were willing to compromise their privacy if their autonomy and personal integrity were respected and if the benefits of sensor-based monitoring outweighed health-related threats. We used these findings and the theoretical outset to create a novel model that takes human motivation into account when using UTAUT.

Keywords: Privacy, Safety, Trade-offs, Older Adults, Unified Theory of Acceptance and Use of Technology (UTAUT), Self-determination Theory (SDT), Healthcare, Sensor-based Monitoring, Wearable.
\end{abstract}

\footnotetext{
${ }^{1}$ Published as: Ehrari, H., Ulrich, F., \& Andersen, H. B. (2020). Concerns and Trade-offs in Information Technology Acceptance: The Balance between the Requirement for Privacy and the Desire for Safety. Communications of the Association for Information Systems, 47. https://doi.org/10.17705/1CAIS.04711
} 


\section{Introduction}

Sensor technologies seem to be a promising approach to help older adults age in their own homes and maintain their wellbeing (Coughlin, Pope, \& Leedle, 2006; Hudson et al., 2005; Pew \& Van Hemel, 2004). For example, sensor-based monitoring can show if an older person's physical activities have dropped significantly and, thus, prompt healthcare professionals to urgently visit them and help the person to avoid hospitalization (Lambert, Harmon, Slade, Whipple, \& Hawkins, 2005). Hence, these new e-health technologies benefit people who have become weakened to some extent. However, at the same time, they bring many challenges to human values (Green, 2012; Grøn, Mattingly, \& Meinert, 2008; Lorincz et al., 2004). For example, automatic toilets have the potential to increase citizens' sense of dignity and autonomy by making them self-reliant. But such devices can also violate people's privacy when the device provides information about their toilet habits. These devices' capability to reveal private and sensitive information about users (Flaherty, 2014) may lead to conflicting concerns regarding the quality of care, illness management (Lambert et al., 2005), and information privacy (Malhotra, Kim, \& Agarwal, 2004). As such, when bringing these monitoring technologies into people's homes, one faces a trade-off between convenience, control, safety, and privacy (Lymberis, 2003).

According to Lowry, Dinev, and Willison (2017), privacy and security issues lie at the center of information systems (IS) research agendas due to their legal, organizational, and cultural mechanisms. At the same time, we only feel safe when we have trust in security. Therefore, we need to examine trade-offs between safety and privacy in e-health and sensor monitoring technologies because many countries have adopted monitoring technologies as part of a larger strategic initiative to add new capabilities to their healthcare sector (Krag, Hansen, \& Nielsen, 2012). For example, the Danish healthcare sector has continuously tried to move away from traditional care consultation such as faceto-face doctor/patient communication to sensor-based technologies that require a higher level of individual responsibility from citizens (Dobrev, Haesner, Hüsing, Korte, \& Meyer, 2008; Harrell, 2009; Kielstra, 2011; Bhanoo, 2010). This shift towards using monitoring technologies raises new questions about scoping their role in healthcare such as their future applications and how one can accept them as clinical tools. As a welfare society, Denmark has a prominent position among the countries with the highest levels of trust in their healthcare system (Jensen \& Svendsen, 2011; OCED, 2011). Thus, we explore if we can find the privacy-safety trade-off in Denmark and if it links to how much trust people place in the healthcare system. Therefore, we examine the following research question:

RQ: How do older adults balance the trade-offs between safety and privacy when using e- health monitoring in a Scandinavian country such as Denmark?

To answer this question, we apply the self-determination theory of motivation (SDT) to the unified theory of acceptance and use of technology (UTAUT). We combine the two theories to explain the relationship between privacy and safety based on our empirical findings from 21 semi-structured interviews with elderly Danish citizens who underwent monitoring via a Fitbit tracker for nine weeks. In practice, we inductively construct a theoretical bridge between SDT and UTAUT.

This paper proceeds as follows: in Section 2, we review and outline the extant literature on SDT and its relation to the UTAUT. We also use UTAUT to explain the trade-offs between privacy and safety. In Section 3 we present the background of the case study and our overall research approach. In section 4, we explore and use the empirical evidence from interviews conducted during a clinical trial on sensor- 
based monitoring technologies to create an evidence-based model that bridges SDT with UTAUT. In Section 5, we present this model. In section 6, we use this model to provide implications for research and a set of normative advice for practice. Overall, our approach enables us to explore opportunities and challenges within monitoring technologies in a Scandinavian context with a focus on balancing concerns and trade-offs between privacy and safety.

\section{Research Background}

In this section, we review and outline the theory on SDT in relation to the UTAUT in the healthcare domain. We start by using SDT to briefly introduce the nature of motivation and the key factors that drive intrinsic and extrinsic motivations. We then combine SDT with the UTAUT to better understand how individuals balance trade-offs between safety and privacy in a healthcare context. We summarize the theory in Table 1. In Table 2, we add the trade-offs to the theory through six propositions that guide our research.

Table 1. Self-determination Theory Applied to Technology Acceptance in the Healthcare Domain

\begin{tabular}{|l|l|l|l|}
\hline Motivation & $\begin{array}{l}\text { Psychological } \\
\text { needs }\end{array}$ & $\begin{array}{l}\text { Statements about } \\
\text { technology acceptance } \\
\text { in the healthcare } \\
\text { domain }\end{array}$ & Examples \\
\hline \multirow{2}{*}{$\begin{array}{l}\text { Intrinsic } \\
\text { (attaining } \\
\text { inherent } \\
\text { satisfaction) }\end{array}$} & Autonomy & $\begin{array}{l}\text { People use health } \\
\text { technology if it makes } \\
\text { them feel more } \\
\text { autonomous. }\end{array}$ & $\begin{array}{l}\text { A step detector can help people to see } \\
\text { improvements in their physical health that } \\
\text { increase their feeling of self-reliance and their } \\
\text { sense of dignity, and thereby their autonomy. }\end{array}$ \\
\cline { 2 - 4 } & & $\begin{array}{l}\text { People use health } \\
\text { technologies to feel } \\
\text { competent to achieve } \\
\text { the desired outcomes. }\end{array}$ & $\begin{array}{l}\text { A health technology that mentally prepares } \\
\text { people to walk may encourage them to walk } \\
\text { more when it improves their physical health. }\end{array}$ \\
\hline $\begin{array}{l}\text { Extrinsic } \\
\text { (achieving } \\
\text { separable } \\
\text { outcomes) }\end{array}$ & Autonomy & $\begin{array}{l}\text { People create an } \\
\text { interpersonal } \\
\text { connection to health } \\
\text { technologies when they } \\
\text { experience them as an } \\
\text { extension of } \\
\text { themselves. }\end{array}$ & $\begin{array}{l}\text { A health technology becomes an extension of } \\
\text { older adults when it aids them in walking. Hence, } \\
\text { people who depend on a walking aid to perform } \\
\text { certain tasks can feel that the technology is an } \\
\text { extension of themselves. }\end{array}$ \\
\hline $\begin{array}{l}\text { People use health } \\
\text { technologies to obtain } \\
\text { their autonomy }\end{array}$ & $\begin{array}{l}\text { People who are at risk of falling can become } \\
\text { dependent on external help. Hence, they may } \\
\text { accept monitoring if it gives them a benefit to } \\
\text { their autonomy that they can move freely } \\
\text { around and get help fast if they fall. }\end{array}$ \\
\hline
\end{tabular}




\begin{tabular}{|l|l|l|l|}
\hline Competence & $\begin{array}{l}\text { People use health } \\
\text { technologies to improve } \\
\text { or gain competences } \\
\text { that provide them with } \\
\text { separable benefits. }\end{array}$ & $\begin{array}{l}\text { A health technology that measures competence } \\
\text { in walking can help people to walk better and } \\
\text { can provide them with separable benefits such } \\
\text { as a new ability to visit their grandchildren. }\end{array}$ \\
\cline { 2 - 3 } & Relatedness & $\begin{array}{l}\text { People use health } \\
\text { technologies if they } \\
\text { relate to the values and } \\
\text { lifestyle in their social } \\
\text { network. }\end{array}$ & $\begin{array}{l}\text { A health technology relates to people by forming } \\
\text { social groups to discuss its advantages and } \\
\text { disadvantages. People who are at risk of falling } \\
\text { may accept others' shared experiences and } \\
\text { recommendations about the beneficial effect of } \\
\text { a fall-detection alarm. }\end{array}$ \\
\hline
\end{tabular}

\section{Self-determination Theory (SDT)}

SDT includes a behavioral change model that explains how motivations influence people's choices (Ryan $\&$ Deci, 2000). Researchers have often used the model to understand what motivates behavioral change that leads to technology adoption (Chen \& Jang, 2010; Lee, Lee, \& Hwang, 2015; Zhang, Zhao, \& Tan, 2008). The cognitive force motivation encourages individuals to perform specific tasks (Amabile, 1997). Research in psychology on behavior change shows that one's actual needs regulate one's motivation to perform a specific task. These theories include Maslow's need hierarchy (Maslow, 1943), McClelland's need theory (Pardee, 1990), Vroom's expectancy theory (Parijat \& Bagga, 2014), and Porter and Lawler's expectancy theory (Lawler \& Suttle, 1973). However, these theories only explain the motivation for performing an action as a whole, whereas they do not consider the type of motivation that regulates people's actions when they make predictions (Deci \& Ryan, 2012; Pardee, 1990). As such, these theories do not distinguish between intrinsic and extrinsic motivation (Gagné \& Deci, 2005). In this paper, we distinguish between intrinsic and extrinsic motivation as Ryan and Deci (2000) have proposed. We define intrinsic motivation as actions that one makes to attain inherent satisfaction over gaining a separable outcome, such as feeling happier or more confident. On the other hand, we define extrinsic motivation as actions that one makes to achieve some separable outcome, such as gaining tangible benefits or obtaining social acceptance. Whether individuals satisfy the two motivators depends on whether they satisfy three basic and universal human psychological needs: autonomy, competency, and relatedness (Deci \& Ryan, 2012; Ng et al., 2012; Wehmeyer, 1998). Autonomy refers to the freedom to choose and the opportunity to determine one's situation. Autonomy refers to the freedom to choose and the opportunity to determine one's situation. Intrinsically motivated autonomy includes the feeling of freedom related to actions in a certain situation (e.g., the feeling of freedom when making a choice), whereas extrinsically motivated autonomy refers to obtaining benefits that create this freedom to choose (e.g., tools that improve freedom to choose). Competence refers to mentally perceiving and physically having the capability to perform the required effort to overcome a challenge. Intrinsically motivated competence includes feeling capable of doing something (e.g., to walk), whereas extrinsically motivated competence refers to the willingness do something that improves or creates capabilities (e.g., being able to walk longer or being able to visit grandchildren). Finally, relatedness refers to the need to view technologies as an extension of oneself or feeling respected or cared for by others. Intrinsically motivated relatedness includes feeling technology as becoming an extension of oneself when one uses it to improve important tasks (e.g., using a walking aid to help walking), whereas extrinsic motivated 
relatedness depends on the values and lifestyle in one's social network (e.g., suggestions by grandchildren to use a fall-detection alarm).

\section{Technology Acceptance Model (TAM)}

IS research has examined what factors influence whether people accept technology for decades (Davis, 1989; Lee, Cheung, \& Chen, 2005; Porter \& Donthu, 2006; Venkatesh, Morris, Davis, \& Davis, 2003). Early theories of technology acceptance include the theory of reasoned action, which explains the determinants of human behavior in a specific context (Davis, Bagozzi, \& Warshaw, 1989). The theory of reason action inspired later theories such as the technology acceptance model (TAM), which researchers specifically designed to investigate the determinants of computer-usage behavior (Davis et al., 1989). Moreover, studies have demonstrated that technology acceptance and technology use closely relate to the self-determination that technology evokes (Dupuy, Consel, \& Sauzéon, 2016; Lee et al., 2015; Przybylski, Rigby, \& Ryan, 2010). For example, Davis, Bagozzi, and Warshaw (1992) adapted the motivational perspectives and added perceived enjoyment to explain why people use computers in the workplace from both extrinsic and intrinsic motivational perspectives. Venkatesh, Speier, and Morris (2002) extended TAM in a motivational framework to examine the influence that pre-training and training environment interventions had on system implementation. The resulting model included extrinsic motivation as a predictor for performance expectancy and intrinsic motivation as a predictor for perceived enjoyment (Teo \& Lee, 2010). Venkatesh et al. (2003) introduced the unified theory of acceptance and use of technology (UTAUT) to explain technology acceptance behavior. Moreover, researchers have used SDT in the technology acceptance domain to understand the factors that motivate people to use technology (Dupuy et al., 2016; Lee et al., 2015; Miller, Deci, \& Ryan, 1988; Nikou \& Economides, 2017). For example, Lee et al. (2015) investigated the relationship between SDT and the UTAUT and confirmed a significant relationship between intrinsic and extrinsic motivational factors and how people perceived gains from the technology and how they enjoyed using it.

\section{Trade-offs Between Safety and Privacy Involved in Technology Acceptance in the Healthcare Domain}

Privacy is an important determinant of whether people accept technologies (e.g., Wilkowska \& Ziefle, 2012). We need to understand this determinant to determine how people perceive and adopt technologies (e.g., Kaapu \& Tiainen, 2016; Lowry et al., 2017). Many researchers have investigated privacy (e.g., Altman, 1975; Li, 2011; Trepte \& Reinecke, 2011; Westin, 2003). All describe privacy as a basic need that enables humans to control the access others impose on them. Most notably, Westin (1967) describes privacy as a dynamic process and outlines that people protect it based on their internal states and external conditions (Westin, 2003). Compared with other privacy theories, the way in which Westin describes privacy suits our study's context as it provides a reasonable foundation for understanding privacy's fundamentals as a psychological concept. One needs such an understanding when studying older adults' the behavioral intention towards using technology and the paradox between the technology's usefulness and how far it protects their privacy.

Researchers have studied individuals' willingness to trade privacy in different contexts. Tsai et al. (2009) investigated privacy concerns related to location sharing and found that providing feedback created a sense of awareness and avoided negative concerns regarding privacy. In another study, Townsend, Knoefel, and Goubran (2011) found that people at risk of losing autonomy willingly traded privacy for 
more independence in most cases. Moreover, Tsai et al. (2009) examined the impact that social networks had on willingness to share location with the inherent keeping privacy and sharing personal information in a social context. Finally, Hong, Ng, Lederer, and Landay (2004) proposed a set of privacy risk models as a general method to refine privacy from an abstract concept into a set of concrete concerns that one could apply to a specific domain or community. However, researchers have not yet explored the balance between privacy and the need for technology.

Research on older adults' technology acceptance reveals that the desire to age safely in their own home drives their technology acceptance (van Hoof, Kort, Rutten, \& Duijnstee, 2011; Peek et al., 2014). However, many studies have raised privacy as it relates to sensor-based monitoring as a major concern (Al Ameen, Liu, \& Kwak, 2012; Demiris et al., 2004; Demiris \& Hensel, 2008; Gaul \& Ziefle, 2009; Li, Lou, \& Ren, 2010; Lowry et al., 2017; Theoharidou, Tsalis, \& Gritzalis, 2016). For example, personal information that older adults share with their formal and informal caregivers can document and quantify their daily routines and habits. People's weakness and frailty might become highly visible to others, which can diminish the differences between private and public information. The potential for 24/7 monitoring creates increased control that limits independence (freedom from dependence) and, thereby, affects people's self-esteem (sense of self-worth and self-respect for own personal values) (Deci \& Ryan, 2012; Ni, Hernando, \& de la Cruz, 2015; Thielke et al., 2012). The privacy implications associated with technologies tend to influence older adults' motivation to accept and integrate sensorbased technologies into their daily lives (Stern, Blanchard, \& Bourgeois, 2014). For example, in a mixedmethods study, Londei et al. (2009) found that 48 percent of their participants rejected the invitation to use the technology due to concerns about privacy.

Researchers have frequently applied the TAM and its extension, the UTAUT, to explain user acceptance of information technologies (Davis, 1986; Taherdoost, 2018). In our research context, we chose to use the UTAUT as a theoretical framework because it explains the underlying process involved in adopting a target behavior in order to prevent perceived risks. The model postulates four determinants of human behavioral intention: performance expectancy (how the technology helps users to attain new gains or benefits), effort expectancy (the degree of ease associated with performing a task), social influence (positive influence from peers), and facilitating conditions (the level of support that the technology provides when users use it).

However, researchers have not yet explored the UTAUT model in relation to privacy implications and the trade-offs between safety and privacy in sensor-based monitoring, which presents a clear gap in the literature. Moreover, researchers developed the UTAUT model in the United States (US) and applied it in a business context (Venkatesh et al., 2003). Applying the model to a study on e-health acceptance and privacy concerns in the Scandinavian public health context will expand our knowledge about the model's robustness in explaining older adults' e-health acceptance behavior.

Similar to the TAM, researchers have increasingly used SDT (Ryan, Patrick, Deci, \& Williams, 2008) to explain the motivational aspects of human behavior when designing and evaluating technologies (Peters, Calvo, \& Ryan, 2018). The theory also guides research in other domains such as job satisfaction (Gagné \& Deci,, 2005), education and e-learning (Ford, Wyeth, \& Johnson, 2012; Chen \& Jang, 2010; Roca \& Gagné, 2008), healthcare (Wehmeyer, 1998; Dupuy et al., 2016), life satisfaction, and selfesteem (Levesque, Stanek, Zuehlke, \& Ryan, 2004). We use SDT because it differs from other motivation theories in that it focuses on autonomous versus controlled motivation and does not assume motivation 
as a whole (Gagné \& Deci, 2005). This differentiation could be important when understanding what motivates or inhibits people to disclose personal information because SDT proposes that people's intentions to perform expected actions depend on whether they satisfy their intrinsic and extrinsic needs (Deci \& Ryan, 2012; Gagné \& Deci, 2005).

Understanding both motivators has important consequences in a healthcare setting and especially in older adults' technology acceptance. The extrinsic motivators explain how external circumstances control people's behaviors, and the intrinsic motivators show people's reasons for letting others control their behavior (Vansteenkiste, Lens, \& Deci, 2006). The better older adults understand their intrinsic motivations and find ways to fulfil them, the better they will be able to autonomously assume personal responsibility and accept external control (Williams, Ryan, Rodin, Grolnick, \& Deci, 1998). Hence, using SDT as a lens to understand intrinsic and extrinsic motivation in healthcare may help researchers better understand older adults' trade-offs between safety and privacy in technologies such as sensor-based monitoring. According to Williams et al. (1998), in healthcare settings, individuals will be more likely to internalize health-related behaviors and maintain behavioral change if they satisfy their autonomy, competence, and relatedness needs. Moreover, as Ryan et al. (2008) have mentioned, satisfying these needs can help people with broad lifestyle changes such as quitting smoking or regulating eating habits and discrete behaviors such as maintaining regular medication use.

In Section 3, we combine SDT with UTAUT to explain our observations about how older adults create a trade-off between safety and privacy. SDT does not directly say anything related to a trade-off between safety and privacy, but, by applying SDT in the context of sensor-based monitoring, we can explain the drivers that influence the intrinsic and extrinsic motivation behind such trade-offs. Such a framework can help explain and predict the underlying challenges related to why people accept or reject technologies with privacy implications. Each construct in the UTAUT and SDT has implications that characterize the types of needs that people face in such situations. Hence, based on discussing the literature and its relation to the trade-off between privacy and safety in healthcare above, we created six propositions to guide our study (see Table 2). 
Table 2. Propositions for Trade-offs between Privacy and Safety Involved in Technology Acceptance in the Healthcare Domain

\begin{tabular}{|c|c|c|c|}
\hline \# & Propositions for technology acceptance & $\begin{array}{l}\text { Relation to } \\
\text { psychological } \\
\text { need }\end{array}$ & $\begin{array}{l}\text { Relation to } \\
\text { motivation }\end{array}$ \\
\hline 1 & $\begin{array}{l}\text { Older adults trade privacy for safety when technology helps } \\
\text { them feel they can overcome health-related challenges. }\end{array}$ & Autonomy & \multirow{3}{*}{ Intrinsic } \\
\hline 2 & $\begin{array}{l}\text { Older adults trade privacy for safety when technology helps } \\
\text { them to feel mentally capable to achieve the desired } \\
\text { outcomes. }\end{array}$ & Competence & \\
\hline 3 & $\begin{array}{l}\text { Older adults trade privacy for safety when they have an } \\
\text { interpersonal connection to a specific technology. }\end{array}$ & Relatedness & \\
\hline 4 & $\begin{array}{l}\text { Older adults trade privacy for safety when technology creates } \\
\text { benefits that prevent external threats and risks harming their } \\
\text { autonomy. }\end{array}$ & Autonomy & \multirow{3}{*}{ Extrinsic } \\
\hline 5 & $\begin{array}{l}\text { Older adults trade privacy for safety when technology helps } \\
\text { them with obtaining physical capabilities that enable them to } \\
\text { achieve their desired outcomes. }\end{array}$ & Competence & \\
\hline 6 & $\begin{array}{l}\text { Older adults trade privacy for safety when their surroundings } \\
\text { recommend technology. }\end{array}$ & Relatedness & \\
\hline
\end{tabular}

\section{Case Study: Elderly People Living at Home}

We base our case study (de Vaus, 2001) on post hoc interviews that we conducted after an activitymonitoring study that lasted over nine weeks from October to December, 2016, in a Danish municipality. In this clinical trial, participants used a Fitbit Charge HR. This study focused on determining whether daily feedback via telephone about the previous day's activity level (number of steps the participants took) would lead to changes in their physical activity. We recruited all participants via an elderly care and activity center in a local municipality in Denmark.

In the activity-monitoring study, we used Fitbit Charge HR as our monitoring device. We chose Fitbit Charge HR as it was one of the latest models in 2016 and met our selection criteria and budget (see Appendix A). The product resembles an ordinary watch, and we selected it due to its technical suitability, easy setup, smartphone compatibility, and price. Before starting the trial, we arranged a 15minute visit with each participant to introduce the device to the participants and instruct them on how to use it. To safeguard the study's ethical standards, we provided all participants with verbal and written information about the study's focus. We then demonstrated how to use the device, explained the kind 
of data it monitored, where we stored the data, and how we protected the participants' privacy. Specifically, we used coded patient identifiers (pseudonyms) in all data processes that we secured on the Fitabase cloud service (see www.fitabase.com) with access control and access log from the university. Before the main study, we installed the Fitbit app along with temporary Fitbit accounts so each participant could follow their data each week. Moreover, we collected and stored the data in compliance with European General Data Protection Regulation (GDPR) regulations. The participants signed an informed consent form that the Technical University of Denmark's ethics committee approved. Finally, Ethical approval for this study was waived by the Committees on Health Research Ethics for the Capital Region of Denmark because "the project does not constitute a health research project, as the purpose of the study is not to achieve new knowledge of the human anatomy but to determine the effect of providing daily feedback on physical activity level and asses awareness of physical activity ..." (H-19005927).

\section{Interview Approach}

Four weeks after the clinical trial, we conducted 21 semi-structured interviews. The 21 participants (18 females (73\%) and three males (27\%)) had a mean age of 85 (range 71-94). We asked them about how they perceived privacy versus safety when being monitored. The two researchers they had been in contact with each day during the tracking trial conducted the interviews at participants' home. The interviews last around 45 minutes each. As a token of gratitude, we provided each participant with a box of chocolates for participating.

The interview included questions about not only privacy but also the use of healthcare technology to support personal health and safety. However, in this paper, we focus only on the following questions:

- Did you feel surveilled during the experiment when we could see your number of steps and hours of sleep?

- Would you feel surveilled if we shared the data with your caregiver/nurse or doctor?

- Did the daily feedback influence your daily activity level or your perception of being monitored?

- Would you accept this monitoring system incorporated into a healthcare device if your municipality (caregiver organization) offered it?

Based on the above questions, we asked the participants to speak freely about their experiences with technologies and monitoring. During the recruitment phase, we briefly raised the issues of privacy and safety. However, participants did not make any spontaneous inquiries about it during the trial study. We audio-recorded the interviews and transcribed all passages about the above issues.

\section{Data Analysis}

To analyze the data, we used a grounded theory approach (Glaser \& Strauss, 1967). We coded each transcript independently and discussed the results to obtain inter-reviewer reliability. We then conducted content analysis (Kvale \& Brinkmann, 2009) by identifying individual themes from the data. Inspired by Layder (1998), we then placed these themes under positive and negative perceptions about safety and privacy and adapted the identified themes to the theoretical grounding of SDT and the UTAUT. 


\section{Results}

In this section, we present our results for the SDT constructs (autonomy, competence, and relativeness) from both intrinsic and extrinsic perspectives. We then outline how older adults trade privacy for safety by combining SDT with the UTAUT.

\section{Autonomy}

From an intrinsic perspective, we found that all the participants wanted to feel autonomy. They wanted to be convinced that being monitored benefited their health and helped them to maintain their independence (Proposition 1). Of the participants, six out of 21 mentioned that, if someone offered them monitoring technologies in the future, a limit on the type of information they must provide should exist. For example, everyone found video monitoring negative and perceived it as a concept that violated their privacy. Because people largely do not notice a wearable sensor, it is better than video monitoring, which makes people's behavior passive and unnatural (Townsend et al., 2011). We define this feeling as a sense of control whereby people do not feel monitored and do not feel a need to act differently. However, we also discovered that sensor-based monitoring made the participants feel safe as the desire to stay independent in their own home had more importance than their concerns about being monitored. In a similar fashion, we found that they would trade privacy and accept video monitoring if it made them feel safe. As one participant stated: "I will of course say yes to it (video monitoring), if it is necessary for my wellbeing.... I would rather be monitored than lie ill for several days." (Kirsten).

Thus, the participants' trade-offs in terms of technology acceptance depended on what behaviors the Fitbit detected and that the monitoring device became a part of their daily lives without being annoying or a burden for them.

From an extrinsic perspective, we found that the participants were positive in their willingness to share personal health data with caregivers. In other words, the elderly participants perceived using health technologies as critical to their ability to inform their external environment about their health status. Correspondingly, the autonomy they desired became associated with the separable benefit of being able to get external help if they would experience any health issues. The participants thus saw the Fitbit as a preventive step (a benefit) that created an extra sense of safety and, thereby, gave them more autonomy in their life (Proposition 4), which relates to performance expectancy in the UTAUT (e.g., Venkatesh et al., 2003). For example, when we asked the participants if they would feel surveilled if we shared the data with their caregiver, two answered as follows: "No, not at all, on the contrary, the doctor must know about it for the sake of my health" (Tim) and "It's hard to tell nurses about health changes, there's so much that's happened.... It's easier to show." (Lis).

Moreover, the participants found that daily feedback via telephone motivating and useful. They felt happy that someone took care of them through monitoring and daily feedback. The phone calls also created a sense of comfort and transparency. We can also view these phone calls as a facilitating condition in the UTAUT that helped the older adults to better use the technology. No participant felt the need to act unnaturally due to the monitoring. The participants' active participation in this feedback process positively influenced their acceptance of the Fitbit wearables. For example, one participant spoke about the daily feedback in the following way: "Daily feedback was very interesting; it was good to know what you [the healthcare service] are measuring" (Henry). 
We also asked the participants' opinions about sensor technologies incorporated into healthcare devices. The participants indicated that they would not mind if they received an offer to be monitored daily or even permanently if their autonomy was respected. For example, they all wanted the opportunity to decide for themselves whether they needed the technology rather than having the decision made for them (Londei et al., 2009). They also wanted health and technology providers to convince them that being monitored was necessary and to fulfil their health-related needs. We define this need to have control over what information others collected about them as a sense of transparency. As one participant stated: "If I feel the need for it, I have to say yes to what is being offered..., but you need to convince me that it is necessary" (Maria).

Other participants indicated that their accepting monitoring technologies for healthcare would create both a sense of comfort and a sense of being watched but it would not feel obtrusive if they used the technology voluntarily. In many ways, the participants perceived the monitoring as intruding on their privacy. However, it also acted as a shield against threats to their health. As one participant expressed: "The thought of someone watching me is somewhat discomfiting. However, if I felt a need to be monitored, I would accept it." (Jenny). Another participant had a different view on being monitored: "I would not feel like I was being monitored; I would feel like people are interested in me" (Inga).

In this regard, a third participant shared her most positive experience with the tracker. Her nurse rejected her after three calls. Finally, she received help from the local emergency service after providing them information about her heart rate changes during the day (measured by our device). "The device saved me from a heart attack because I could follow my heart rate.... If I did not have the device, I would not have been aware that I needed urgent help." (Lone).

\section{Competence}

From an intrinsic perspective, we found that the participants would willingly accept any kind of monitoring if it made them feel that they would achieve a desired outcome (Proposition 2). As such, the technology's ability to make them feel better (e.g., having more energy because they walked more) increased their willingness to be monitored. This finding indicates that self-rated cognitive abilities play a major role in how people perceive privacy and their use of technology (for elaboration, see Tacken, Marcellini, Mollenkopf, Ruoppila, \& Széman, 2005; Ziefle \& Carsten, 2010). Moreover, the participants who found the device useful also felt mentally competent to use and control the technology to an extent where it could effectively improve their physical abilities. A participant who felt mentally competent in walking and improving her existing capabilities with the Fitbit as a step-counter device stated: "When you are provided with numbers of steps (daily feedback calls), you want to go for an extra walk" (Else).

In contrast, those participants who found the Fitbit useless were mentally and physically weak and did not feel competent in improving their capabilities nor able to control the outcome of their health situation. The following quotes shows participants who felt less competent in improving their walking capabilities with the Fitbit as a step counter device: "The daily call has got me to think about how much I am moving, and I had a bad conscience about how much I moved" (Maria) and "It has been motivating to get feedback, but at the moment I am walking poorly" (Gerda).

From an extrinsic perspective, competence involves the need to improve or gain previously absent skills -in our case, those physical capabilities that relate to health and wellbeing (Proposition 5). 
Extrinsic competence relates to effort expectancy in the UTAUT model (Peters et al., 2018; Venkatesh et al., 2003) as it addresses how easy it is for users to perform a task. Thus, competence from an extrinsic perspective relates to what benefits people can gain that could enable them to become more effective in performing a specific task and the ease of performing such a task. From this perspective, our participants appreciated the Fitbit because it improved their competence without the need for extensive efforts to use it. Therefore, we found that such extrinsic motivation to use the technology came from the need to improve or gain competence. For example, by monitoring our participants daily, which gave them data about their physical progress through the number of steps they walked, we could build up confidence in their own beliefs associated with their competence to walk. As such, the daily monitoring and feedback made them better recognize their current competency in walking and gave them competence to walk more. As two participants explained:

Daily feedback made me think about how much I am capable of moving around. When I got the actual numbers of steps, I had a bad conscience about how much I actually moved. I haven't felt monitored in any way [...] It is very good that someone is watching if I'm doing too little. (Kirsten)

I didn't feel monitored. It's nice that there is someone who takes an interest in us old people. It's been fine, also because l expected to get something out of it. (Jenny)

Hence, the benefit of improving their competence to walk outweighed the feeling of being monitored. Moreover, the introduction to the device we provided to the participants also gave them a new competence in using the device. This competence also relates to effort expectancy as, once the participants felt competent to use the device, it became less of an inconvenience and they became more motivated to use it. For example, they noted that the device was easy to put on and they sometimes forgot they were even wearing it. However, they had mixed reactions to the device itself. Some participants felt less competent in improving their mental and physical capability (intrinsically unmotivated) did not like the device. However, those participants who felt competent in improving or gaining capabilities (intrinsically motivated) or experienced benefits in their competencies from using the device (extrinsically motivated) did not care about design or functionality and also felt competent to use the device. As two participants stated: "It has been nice to go around wearing a digital watch" (Henry) and "I just assumed it was an ordinary watch; I didn't even think it monitored something on me" (Paula).

The device's comfort level and fashion-based factors represent another notable aspect related to whether users would accept any device in the future. The device's physical look played a major role in making the participants feel competent and comfortable and in reducing their concerns about privacy. For instance, its familiarity meant the participants avoided drawing negative attention and possible stigmatization (Luijkx, Peek, \& Wouters, 2015) since it looked like a digital watch. Consequently, most participants felt competent in using it and assumed it was a digital watch, which reduced negative concerns regarding their privacy.

\section{Relatedness}

Relatedness from the intrinsic perspective refers to how people have an interpersonal connection with a technology as an extension of oneself, which motivates a specific behavior (Elliot, Sheldon, Kasser, \& Kim, 2001). This sense of relatedness plays a major role inavoiding those concerns and negative perceptions people have about using technologies. . For example, older adults who suffer from declining 
health will more willingly accept monitoring and feel more related to monitoring technologies compared to older adults who do not suffer from impairments ( $\mathrm{Ng}$ et al., 2012). In a similar fashion, our findings indicate that older adults who face or have faced a health decline (e.g., asthma attacks, broken hips and not being discovered when they have fallen) depend more on the technology to keep them safe (Proposition 3). Even though they perceive surveillance as being negative, they will accept monitoring and have less concern about their privacy because it is a helpful tool to keep them safe. Hence, their previous experience of danger has increased their awareness of possible threats and boosted their willingness to accept sensor-based monitoring. As one participant noted: "I am used to someone watching me, I am only glad about that, I think it is good.... When it is something that neither hurts nor tastes awful, then I think you should accept it" (Kirsten).

From an extrinsic perspective, the participants mentioned different factors that made them feel unconcerned about sensor-based monitoring. In line with Venkatesh et al.'s (2003) UTAUT, we found that membership in a social network (social influence) influenced how they felt about being watched and using the technology (Proposition 6). For example, their grandchildren expressed enthusiasm about the technology, which created a sense of security and comfort where they lacked concern for privacy issues. As a participant explained: "My grandchildren are encouraging me.... They think it's cool, to see their old grandma with such a device" (Maria).

Furthermore, most participants indicated a fear of lying undiscovered. They expressed their concerns by referring to frightening talk about undiscovered bodies. This fear made the participants more willing to accept sensor-based monitoring. As one said: "Whenever you hear that someone's body was undiscovered for several days, it raises concerns about oneself" (Lily).

In total, five out of 21 participants expressed excitement about continuing to use and planned to use the Fitbit tracker in the future. Among them, one felt a sense of relatedness to the device and bought her own after the study. She wanted to track her activity level each day in order to be sure that she reached her daily activity goals. All the participants said they did not feel monitored when we asked them: "Did you feel monitored during the experiment when we could see the number of steps taken/sleeping hours?". Instead, the participants were relaxed about how others might use their data. They mentioned location tracking and video monitoring as factors that would threaten their privacy; however, the participants would accept them if they made them feel safe.

\section{A Model of the Contextual and Personal Factors that Balance the Trade-offs Between Privacy and Safety}

In line with Ryan and Deci's (2000) work on motivation, we show that intrinsic motivation relates to factors that can engage people in behaviors that make them feel better about themselves, whereas extrinsic motivation relates to factors that can engage people in behaviors that give them tangible rewards, provide social acceptance, or enable them to prove something to themselves. Both types of motivation have a significant impact on how people accept technologies and their willingness to trade privacy for safety. In this section, we combine the initial literature study and our results into a model of trade-offs between privacy and safety in technology acceptance. During the interviews, we frequently discussed the balance between the desire for safety and the requirement for privacy with the participants. The results revealed various subthemes that relate to different aspects of human psychology. To further explain and predict the participants' behavioral intentions and the trade-offs 
between safety and privacy, we present our results according to the UTAUT and SDT themes in Figure 1. The model summarizes the developed theory and combines the SDT (psychological needs) and the two UTAUT constructs (behavior intention and use behavior). In this model, we discuss how to overcome the challenges associated with trade-offs between privacy and safety in technology acceptance. We illustrate how people develop autonomous extrinsic motivation and self-regulation through internalization and integration. Moreover, we outlined the individual differences in general motivational orientations, and how the understanding of psychological needs can help people maintain their health function.

Our findings confirm all our propositions about older adults' willingness to trade privacy for safety. As Figure 1 shows, the psychological needs of autonomy, competence, and relatedness create behavioral intentions. Here, older adults assess a technology according to how it satisfies their perceived needs (maintaining consistency between their values and their behaviors). The need for autonomy can lead to their trading privacy for safety when users feel they can control what happens (intrinsically motivated). Performance expectancy (i.e., older persons' confidence in the health device's performance to inform the outside world about a health issue) fulfills such autonomy. Here, older adults reduce their concerns about privacy depending on how far the technology provides a shield against threats to their health (extrinsically motivated to prove something to oneself). Moreover, the need for competences can reduce privacy concerns when the technology provides new ways to make users feel better about themselves (intrinsically motivated). Effort expectancy influences competencies. Here, older adults will willingly trade privacy for the new competencies they gain, the ability to easily use the device, and a reduction in the stigmatization they experience when using the device (extrinsically motivated). Finally, the need for relatedness can mediate negative privacy concerns when clear health threats or functional declines that enable the older adults to relate to the technology exist (intrinsically motivated). Such relatedness is further boosted by the impact from social influence. Such social influence originates from social networks that provide recommendations about the technology from next of kin, caregivers, or friends (extrinsically motivated). SDT accounts for such ambiguity between intrinsic and extrinsic motivations (Patrick \& Williams, 2012). In health contexts in particular, it is common that the patients must undergo radical lifestyle changes. Such changes include that patients must accept monitoring, provide personal data to detect their diseases, and trade safety for privacy. As such, others' opinion is an important extrinsic factor that can help patients to autonomously self-regulate by changing their own values and behavior according to others' values and behavior. For example, patients may choose to use sensor-based monitoring because their municipal nurse or doctor will not help them unless they use the device and they risk losing the gained benefits from the increased safety. This interjected regulation involves engaging in behavior out of some sense of guilt, obligation, or fear of losing benefits (Patrick \& Williams, 2012). However, motivation can also be intrinsic when people who need to prove something to themselves want to enhance their self-worth. As such, patients may give up privacy and accept monitoring because they feel guilty about the emotional and financial disorder their relatives would face if they are injured or because they simply believe it is important for their health or their goals in life such as maintaining an independent life and living longer and healthier. 


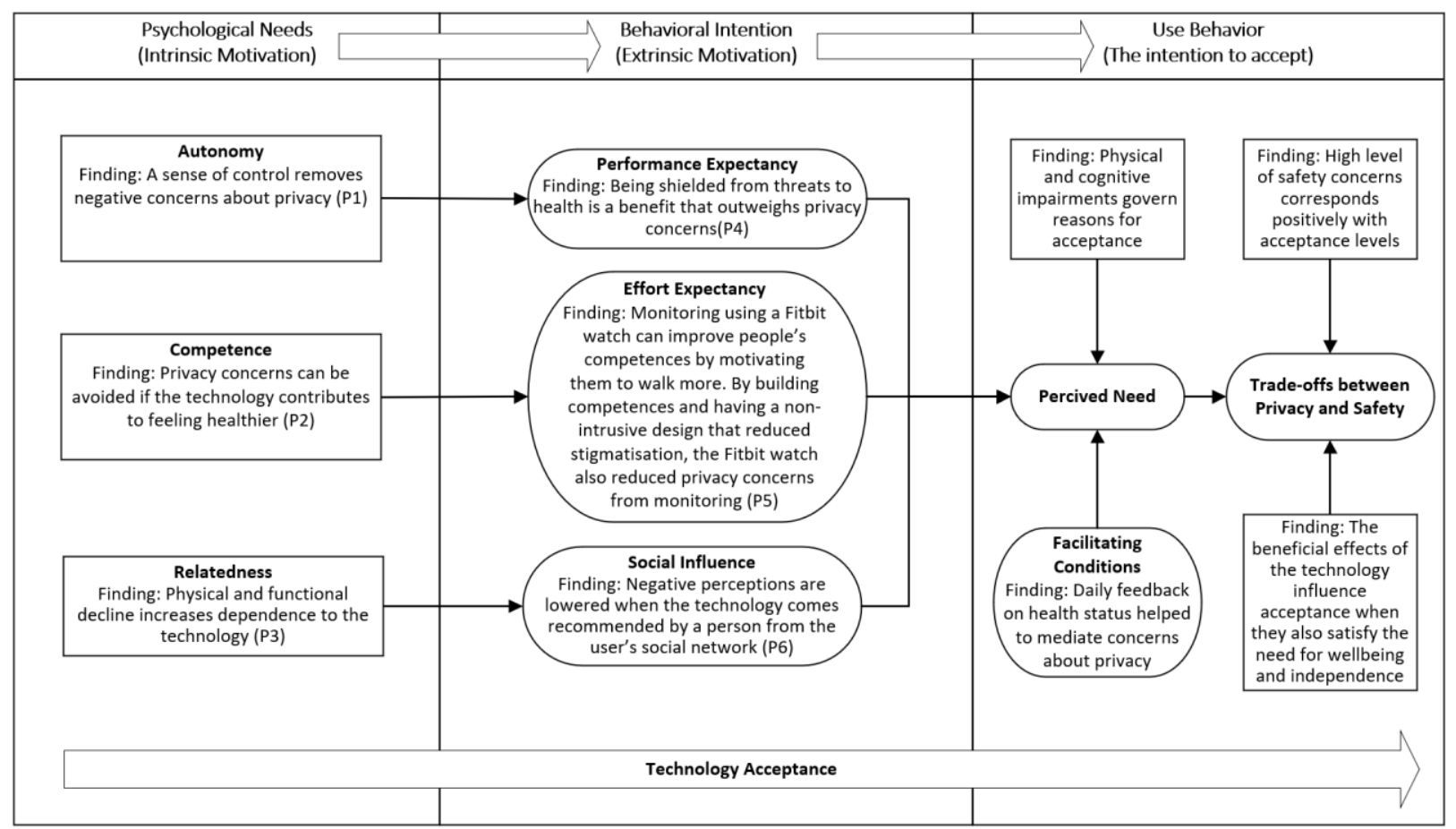

Figure 1. A. Model Showing the Balance of Trade-offs Between Privacy and Safety in Technology Acceptance

Hence, use behavior refers to the intention to accept the technology that the compatibility between intrinsic and extrinsic needs influences. We found that the daily feedback provided a facilitating condition that helped mediate the concerns the older adults had about their privacy by providing transparency about the data the device collected. However, psychological needs vary over time and according to one's situation. As such, they depend on people's health and day-to-day needs (Peek et al., 2016; Townsend et al., 2011). As Figure 2 shows, older adults need to satisfy their psychological need to feel safe before they gain enough self-esteem (sense of self-worth, personal value) to feel that technology threatens their privacy (see also Maslow, 1943).

As such, we cannot easily define the exact need and the exact factor that weighs heaviest in the individual trade-offs. Our findings indicate that all our participants positively perceived the sensor-based monitoring and expressed interest in using it, particularly when they found it easy to use, when it conveniently fitted into their daily routines, and when it benefitted their health and wellbeing. The participants were willing to trade their privacy for the technological benefits that satisfied their needs, especially those benefits that they needed to maintain their health or independence. We found that balancing the requirement for privacy with the desire for safety should be compared to the needs of the individual. Hence, the need in older adults to stay safe has a positive influence on their acceptance of the monitoring technology despite it having privacy issues. In other words, older adults perceive sensors and related technologies as tools that can satisfy their need for safety at an acceptable cost of privacy. This finding concurs with existing work in psychology that outlines safety and independence as a basic human need (Elliot et al., 2001; Maslow, 1943; Thielke et al., 2012). 


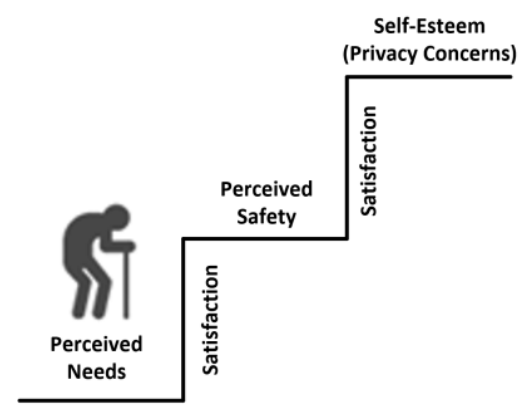

Figure 2. The Importance of Needs in the Trade-offs Between Safety and Privacy

\section{Discussion}

We began this study by asking how older adults balance their trade-offs between safety and privacy when using e-health monitoring in a Scandinavian country such as Denmark. To answer this question, we examined whether using a wearable sensor (Fitbit Charge HR) for nine weeks led to any concerns regarding privacy and safety over time among 21 older adults.

Our research demonstrates that, overall, wearables represent an attractive option for sensors because many of our participants did not have concerns about their privacy and indicated that they found their safety more important than giving up privacy. All participants indicated that the sensor-based monitoring could fulfil their strong desire to stay in their own home in the future by minimizing unnecessary control visits by healthcare professionals. Our findings confirm prior studies on balancing trade-offs between privacy and safety (e.g., Bailey, Foran, Ni Scanaill, \& Dromey, 2011; Coughlin et al., 2006; Lymberis, 2003; Ni et al., 2015; Pol et al., 2016; Silveira, van het Reve, Daniel, Casati, \& De Bruin, 2013; Tacken et al. 2005; Townsend et al., 2011; Ziefle \& Carsten, 2010).

Since our participants did not express many privacy concerns, we conclude that the privacy paradox appeared less strongly among our participants. As in Baek's (2014) work, how the technology's benefits related to participants' needs seemed to govern how the latter viewed privacy. Our findings build on a small group of senior citizens in Denmark, and the strong trust culture in the country can explain the strong perceptions they had. Due to this trust, people are more willing to share their data with general practitioners, municipal caregivers, and other institutions. It seems that high trust creates a relaxed attitude to information privacy and possible loss of privacy. This finding concurs with Norberg, Horne, and Horne (2007), who found that high levels of trust increase people's willingness to disclose information.

Furthermore, we used our findings to combine SDT with the UTAUT. Our model fills an important gap in the literature concerning the psychological aspects of trade-offs between safety and privacy involved in technology acceptance (see Figure 1). This important contribution illustrates that trade-offs leading to technology acceptance require technological benefits that satisfy humans' psychological needs. As such, we need to understand the compatibility between perceived needs and expected benefits to ensure patients (especially Scandinavian citizens in a welfare state system) accept healthcare devices and their technologies in the long term (e.g., Rupp, Michaelis, McConnell, \& Smither, 2018; Schwarzer, 2008). Trading some of the world's most high-quality services for sensor-based monitoring might raise conflicting concerns regarding privacy and confusion regarding the trade-offs between safety and privacy. Therefore, we make an important contribution for older adults, clinicians, and other technology 
providers. Sensor technologies not only help older adults but also help caregivers by making tasks more efficient; for example, by allowing them to access the patient's real-time data anywhere and at any time. This opportunity may allow caregivers to take effective action related to each patient's situation (see Lambert et al., 2005). Furthermore, understanding older adults' perception and trade-offs between safety and privacy can help caregivers to understand people's attitudes towards other technologies. This understanding can help caregivers make older adults realize that they are increasingly responsible for themselves when subscribing to health services that the welfare state previously provided. Hence, our research explains the different aspects involved, the context, stakeholders' perceived interests, the values that shape the trade-off, and the changes that these technologies bring with them.

\section{Implications for Research}

Based on the above discussion, we provide a different perspective by investigating the trade-offs between the need to feel safe and the need for privacy. Our research concurs with prior research that found that older adults would willingly trade privacy for autonomy (e.g., Townsend et al., 2011). However, we added the perspective of motivation from SDT and connected it with the trade-off behavior identified in the prior literature. Moreover, as we outline in Section 1, we conducted this research in a Scandinavian healthcare context, which features problems and benefits that stem from a paradigm shift in the welfare state from universal care to individual responsibility. Hence, our study adds new knowledge about how older adults perceive and accept novel technologies in a safety-enhancing healthcare device in a Scandinavian context. Hence, we contribute to our knowledge about the tradeoffs that older adults make between safety and privacy by clarifying what they individually find important. This new knowledge can add a new perspective to how designers design monitor-based healthcare devices (e.g., Hong et al., 2004; Peters et al., 2018) that has previously focused on humancomputer interaction (Davis et al., 1992; Ford et al., 2012; Peters et al., 2018). We also provide a fresh perspective to the technology implementation literature (e.g., (Fischer, David, Crotty, Dierks, \& Safran, 2014; Legrisa, Inghamb, \& Collerettec, 2003; Schaper \& Pervan, 2007; Yusif, Soar, \& Hafeez-Baig, 2016) by outlining the key factors relating to trade-offs between privacy and safety. Hence, further investigation into these behavioral processes could outline additional trade-offs to the ones we covered in this study. We encourage future research to further expand on our study, such as by focusing on other important trade-offs or using a longitude research setting (Peters et al. 2018).

In addition, technology acceptance literature has existed for decades. Researchers have frequently applied the UTAUT to explain user acceptance of information technologies (Davis, 1986). In this study, we add new knowledge to the literature by demonstrating that technology acceptance and technology usage behavior closely relate to how people perceive self-determination that technology elicits (e.g., Peters et al., 2018). Based on SDT, we explain people's internal beliefs according to their own preferences, interests, and abilities and combine this theory with the impact that external factors have on internal beliefs as per the UTAUT. Although researchers have applied the UTAUT and its extended versions to technology use, they have scarcely examined how older adults perceive healthcare technologies (e.g., King \& He, 2006; Legris, Ingham, \& Collerette, 2003; Schepers \& Wetzels 2007). To bridge this gap, we contribute with a behavioral approach to examine information privacy and, thus, contribute to the security and privacy literature in IS (Lowry et al. 2017). We encourage future research to extend this model of the trade-off behavior involved in technology acceptance. 
Finally, our empirical evidence limits our study. We conducted this study based on 21 Danish older adults and not it in an operational setting; the associated risks/benefits might differ when experienced during real implementation. Trading some of the world's most high-quality services for sensor-based monitoring might also raise conflicting concerns such as worries about trading doctor-patient relations for self-monitoring. Moreover, we did not address how other people's technology use affects motivation or how intrinsic motivation can affect extrinsic motivation and vice versa. Therefore, we call for more research on how older adults perceive sensor-based monitoring in healthcare.

\section{Implications for Practice}

To understand the trade-off between privacy and safety, one needs to understand users' needs in depth. To avoid negative privacy concerns in sensor-based monitoring, we found that older adults must be able to identify with technology's value and the benefits (see also Gagné \& Deci, 2005; Lee et al., 2015; Miller et al., 1988; Ng et al., 2012; Williams et al., 1998). With the behavioral regulations that sensor-based monitoring provide, older adults can feel greater freedom and more security in their daily lives. This change in behavior results from an alignment between the technology, their personal goals, and their psychological needs (see also Gagné \& Deci 2005; Ryan et al., 2008; Ryan \& Deci, 2000). For example, the participants who identified themselves as being at risk valued monitoring and wanted to trade their privacy for the beneficial change or therapeutic effect that the sensor technology provided. Those participants who did not feel any risk (no health decline) wanted to be convinced about monitoring's potential before fully committing. Hence, their trading behavior highly depended on what technology offered in relation to their actual psychological needs. However, these psychological needs can vary over time depending on individual health and day-to-day needs. Therefore, we cannot easily define the exact needs and factors that weigh heaviest in the individual trade-off situation.

Furthermore, the benefits that older adults perceived in sensor-based monitoring somehow seem paradoxical. On the one hand, it enhances autonomy, while, on the other, it limits individual freedom and violates personal autonomy (Deci \& Ryan, 2012). Based on our findings, we found that, for practitioners in sensor-based monitoring, the following bullet points outline how to handle trade-offs concerning the privacy-safety paradox in a Scandinavian healthcare setting:

- Sense of transparency: older adults want control over their data. Consequently, practitioners should inform them about the types of parameters they measure and let them decide what data they want to provide. For example, practitioners should develop a set of guidelines that covers what and why they measure something and how it benefits the older adult.

- Data awareness: older adults want to decide for themselves whether they need technology based on functional and psychological needs. Consequently, practitioners should provide older adults with feedback including how they interpret results such as their health status related to their current needs. For example, practitioners can use user interfaces with easy-to-understand data visualization that is designed for older adults.

- Respect for personal autonomy: older adults have certain routines and rules in their personal lives. Consequently, practitioners should consider such personal factors when designing and implementing this class of healthcare device that may intrude on personal privacy. For example, practitioners can deploy modular systems that individuals can adapt to their specific needs and preferences. 
- Familiar designs: older adults may tend to distrust novel technologies. Consequently, practitioners should try to deploy a product design that this user group finds familiar to ensure that they do not perceive such technologies negatively or experience stigma when their design indicates "disability". For example, the Fitbit Charge HR resembles a bracelet watch and, thus, resembles other devices that older adults know.

- Influence of social networks: older adults' social networks highly influence them. Consequently, when practitioners want to reduce negative stigma when offering these technologies, they should recognize such social networks. For example, we found that positive influence in the social network also had a positive effect on technology acceptance.

\section{Conclusion}

In conclusion, the older adults we interviewed in this study valued the potential of a sensor-based monitoring device and perceived that it could ensure their safety and contribute to their desire to remain independent in their own homes. Moreover, self-rated cognitive and functional ability plays a major role in whether people accept such technologies. People who found themselves at risk were more willing to accept monitoring in return for reduced privacy compared to people who felt no risks. In our conceptual model, we outlined the importance of psychological needs in relation to trade-off behavior. Our findings indicate that people may trade privacy due to extrinsic reasons; for example, when their safety is threatened. These trade-offs may become more effective when older adults internalize the benefit of being monitored; for example, when safety-threatened people realize that the technology contributes to their safety. Through this study, we contribute to the ongoing discussion on technologybased trade-offs involved in technology acceptance by aligning concerns about privacy versus those about safety and those about autonomy versus those about control. Moreover, we added new knowledge to the UTAUT by combining it with SDT and provide recommendations and guidelines for research and practice in sensor-based monitoring in a Scandinavian healthcare context.

\section{Acknowledgments}

The work presented in this paper is part of project REACH (http:\crreach2020.eu) that received funding from the European Union's Horizon 2020 Research and Innovation program under grant agreement No 690425. We thank our REACH partners for support and to all project contributors: our very dedicated participating citizens of the three care centers, Bredebo, Solgård, and Virumgård, and also our student assistants. Moreover, we thank the CAIS review team who provided valuable feedback on the paper. 


\section{References}

Al Ameen, M., Liu, J., \& Kwak, K. (2012). Security and privacy issues in wireless sensor networks for healthcare applications. Journal of Medical Systems, 36(1), 93-101.

Altman, I. (1975). The environment and social behaviour: Privacy, personal space, territory and crowding. Monterey, CA: Brooks-Cole Publishing Co.

Amabile, T. M. (1997). Motivating creativity in organizations: On doing what you love and loving what you do. California Management Review, 40, 39-58.

Baek, Y. M. (2014). Solving the privacy paradox: A counter-argument experimental approach. Computers in Human Behavior, 38, 33-42.

Bailey, C., Foran, T. G., Ni Scanaill, C., \& Dromey, B. (2011). Older adults, falls and technologies for independent living: A life space approach. Ageing and Society, 31(5), 829-848.

Bhanoo, S. N. (2010). Denmark leads the way in digital care. The New York Times. Retrieved from https://www.nytimes.com/2010/01/12/health/12denmark.html

Chen, K. C., \& Jang, S. J. (2010). Motivation in online learning: Testing a model of self-determination theory. Computers in Human Behavior, 26(4), 741-752.

Coughlin, J. F., Pope, J. E., \& Leedle, B. R. (2006). Old age, new technology, and future innovations in disease management and home health care. Home Health Care Management and Practice, 18(3), 196207.

Davis, F. D. (1986). A technology acceptance model for empirically testing new end-user information systems: Theory and results (doctoral thesis). Massachusetts Institute of Technology, Massachusetts.

Davis, F. D. (1989). Perceived usefulness, perceived ease of use, and user acceptance of information technology. MIS Quarterly, 13(3), 319-340.

Davis, F. D., Bagozzi, R. P., \& Warshaw, P. R. (1989). User acceptance of computer technology: A comparison of two theoretical models. Management Science, 35(8), 982-1003.

Davis, F. D., Bagozzi, R. P., \& Warshaw, P. R. (1992). Extrinsic and intrinsic motivation to use computers in the workplace. Journal of Applied Social Psychology, 22(14), 1111-1132.

de Vaus, D. A. (2001). Research design in social research. Thousand Oaks, CA: Sage.

Deci, E. L., \& Ryan, R. M. (2012). Self-determination theory in health care and its relations to motivational interviewing: A few comments. International Journal of Behavioral Nutrition and Physical Activity, 9, 1-6.

Demiris, G., \& Hensel, B. K. (2008). Technologies for an aging society: A systematic review of "smart home" applications. Yearbook of Medical Informatics, 33-40.

Demiris, G., Rantz, M. J., Aud, M. A., Marek, K. D., Tyrer, H. W., Skubic, M., \& Hussam, A. A. (2004). Older adults' attitudes towards and perceptions of "smart home" technologies: A pilot study. Medical Informatics and the Internet in Medicine, 29(2), 87-94. 
Dobrev, A., Haesner, M., Hüsing, T., Korte, W. B., \& Meyer, I. (2008). Benchmarking ICT use among general practitioners in Europe: Final report. Bonn: Empirica.

Dupuy, L., Consel, C., \& Sauzéon, H. (2016). Self determination-based design to achieve acceptance of assisted living technologies for older adults. Computers in Human Behavior, 65, 508-521.

Elliot, A. J., Sheldon, K. M., Kasser, T., \& Kim, Y. (2001). What is satisfying about satisfying events? Testing 10 candidate psychological needs. Journal of Personality and Social Psychology, 80, 325-339.

Fischer, S. H., David, D., Crotty, B. H., Dierks, M., \& Safran, C. (2014). Acceptance and use of health information technology by community-dwelling elders. International Journal of Medical Informatics, 83(9), 624-635.

Flaherty, J. L. (2014). Digital diagnosis: Privacy and the regulation of mobile phone health applications. American Journal of Law \& Medicine, 40(4), 416-441.

Ford, M., Wyeth, P., \& Johnson, D. (2012). Self-determination theory as applied to the design of a software learning system using whole-body controls. In Proceedings of the 24th Australian ComputerHuman Interaction Conference.

Gagné, M., \& Deci, E. L. (2005). Self-determination theory and work motivation. Journal of Organizational Behavior, 26(4), 331-362.

Gaul, S., \& Ziefle, M. (2009). Smart home technologies: insights into generation-specific acceptance motives. In A. Holzinger \& K. Miesenberger (Eds.), HCl and usability for e-inclusion (LNCS vol. 5889). Berlin: Springer.

Glaser, B. G., \& Strauss, A. L. (1967). The discovery of grounded theory: Strategies for qualitative research. Chicago, IL: Aldine.

Green, D. (2012). Review of prevention of treatment failure. The use of measuring, monitoring, and feedback in clinical practice. Clinical Child Psychology and Psychiatry, 17(2), 219-220.

Grøn, L., Mattingly, C., \& Meinert, L. (2008). Kronisk hjemmearbejde. Sociale håb, dilemmaer og konflikter i hjemmearbejdsnarrativer i Uganda, Danmark og USA. Tidskrift for Forskning i Sygdom Og Samfund, 9, 71-95.

Harrell, E. (2009). In Denmark's electronic health records program, a lesson for the U.S. Time. Retrieved from http://content.time.com/time/health/article/0,8599,1891209,00.html

Hong, J. I., Ng, J. D., Lederer, S., \& Landay, J. A. (2004). Privacy risk models for designing privacy-sensitive ubiquitous computing systems. In Proceedings of the Conference on Designing Interactive Systems Processes, Practices, Methods, and Techniques.

Hudson, L. R., Hamar, G. B., Orr, P., Johnson, J. H., Neftzger, A., Chung, R. S., Williams, M. L., Gandy, W. M., Crawford, A., Clarke, J., \& Goldfarb, N. I. (2005). Remote physiological monitoring: Clinical, financial, and behavioral outcomes in a heart failure population. Disease Management, 8(6), 372-381.

Jensen, C., \& Svendsen, G. T. (2011). Giving money to strangers: European welfare states and social trust. International Journal of Social Welfare, 20(1), 3-9. 
Kaapu, T., \& Tiainen, T. (2016). Consumers' views on privacy in e-commerce. Scandinavian Journal of Information Systems, 21(1), 3-22.

Kielstra, P. (2011). Future-proofing Western Europe's healthcare-a study of five countries. Economist. Retrieved from https://eiuperspectives.economist.com/healthcare/future-proofing-western-europeshealthcare

King, W. R., \& He, J. (2006). A meta-analysis of the technology acceptance model. Information and Management, 43(6), 740-755.

Krag, A., Hansen, B., \& Nielsen, E. (2012). EHealth in Denmark. Retrieved from https://www.sum.dk/ /media/Filer\%20-\%20Publikationer_i_pdf/2012/SundhedsIT/Sundheds_IT_juni_web.ashx

Kvale, S., \& Brinkmann, S. (2009). InterViews: Learning the craft of qualitative research interviewing. Thousand Oaks, CA: Sage.

Lambert, M. J., Harmon, C., Slade, K., Whipple, J. L., \& Hawkins, E. J. (2005). Providing feedback to psychotherapists on their patients' progress: Clinical results and practice suggestions. Journal of Clinical Psychology, 61(2), 165-174.

Lawler, E. E., \& Suttle, J. L. (1973). Expectancy theory and job behavior. Organizational Behavior and Human Performance, 9(3), 482-503.

Layder, D. (1998). Sociological practice-linking theory and practice. Thousand Oaks, CA: Sage.

Lee, M. K. O., Cheung, C. M. K., \& Chen, Z. (2005). Acceptance of Internet-based learning medium: The role of extrinsic and intrinsic motivation. Information and Management, 42(8), 1095-1104.

Lee, Y., Lee, J., \& Hwang, Y. (2015). Relating motivation to information and communication technology acceptance: Self-determination theory perspective. Computers in Human Behavior, 51, 418-428.

Legris, P., Inghamb, J., \& Collerettec, P. (2003). Why do people use information technology? A critical review of the technology acceptance model. Information \& Management, 40(3), 191-204.

Levesque, C., Stanek, L. R., Zuehlke, A. N., \& Ryan, R. M. (2004). Autonomy and competence in German and American university students: A comparative study based on self-determination theory. Journal of Educational Psychology, 96(1), 68-84.

Li, M., Lou, W., \& Ren, K. (2010). Data secutiry and privacy in wireless body area networks. IEEE Wireless Communications, 17(1), 51-58.

Li, Y. (2011). Empirical studies on online information privacy concerns: Literature review and an integrative framework. Communications of the Association for Information Systems, 28, 453-496.

Londei, S. T., Rousseau, J., Ducharme, F., St-Arnaud, A., Meunier, J., Saint-Arnaud, J., \& Giroux, F. (2009). An intelligent videomonitoring system for fall detection at home: Perceptions of elderly people. Journal of Telemedicine and Telecare, 15(8), 383-390. 
Lorincz, K., Malan, D. J., Fulford-jones, T. R. F., Nawoj, A., Clavel, A., Shanyder, V., Mainland, G., Welsh, M., \& Moulton, S. (2004). Sensor networks for emergency response: Challenges and opportunities. Pervasive Computing, 3(4), 16-23.

Lowry, P. B., Dinev, T., \& Willison, R. (2017). Why security and privacy research lies at the centre of the information Systems (IS) artefact: Proposing a bold research agenda. European Journal of Information Systems, 26(6), 546-563.

Luijkx, K., Peek, S., \& Wouters, E. (2015). “Grandma, you should do it-its cool”: Older adults and the role of family members in their acceptance of technology. International Journal of Environmental Research and Public Health, 12(12), 15470-15485.

Lymberis, A. (2003). Smart wearable systems for personalised health management: Current R\&D and future challenges. In Proceedings of the 25th Annual International Conference of the IEEE Engineering in Medicine and Biology Society.

Malhotra, N. K., Kim, S. S., \& Agarwal, J. (2004). Internet users' information privacy concerns (IUIPC): The construct, the scale, and a causal model. Information Systems Research, 15(4), 336-355.

Maslow, A. (1943). A theory of human motivation. Psychological Review, 50(4), 370-396.

Miller, K. A., Deci, E. L., \& Ryan, R. M. (1988). Intrinsic motivation and self-determination in human behavior. Contemporary Sociology, 17(2).

Ng, J. Y. Y., Ntoumanis, N., Thøgersen-Ntoumani, C., Deci, E. L., Ryan, R. M., Duda, J. L., \& Williams, G. C. (2012). "Self-Determination Theory Applied to Health Contexts: A Meta-Analysis," Perspectives on Psychological Science.

Ni, Q., Hernando, A. B. G., \& de la Cruz, I. P. (2015). The elderly's independent living in smart homes: A characterization of activities and sensing infrastructure survey to facilitate services development.

Sensors, 15, 11312-11362.

Nikou, S. A., \& Economides, A. A. (2017). Mobile-based assessment: Integrating acceptance and motivational factors into a combined model of self-determination theory and technology acceptance. Computers in Human Behavior, 68, 83-95.

Norberg, P. A., Horne, D. R., \& Horne, D. A. (2007). The privacy paradox: Personal information disclosure intentions versus behaviors. Journal of Consumer Affairs, 41(1), 100-126.

OCED. (2011). Society at a glance 2011: OECD social indicators. Retrieved from http://www.oecd.org/social/societyataglance.htm

Pardee, R. L. (1990). Motivation theories of Maslow, Herzberg, McGregor \& McClelland: A literature review of selected theories dealing with job satisfaction and motivation. U.S. Department of Education. Retrieved from https://files.eric.ed.gov/fulltext/ED316767.pdf

Parijat, P., \& Bagga, S. (2014). Victor Vroom's expectancy theory of motivation-an evaluation. International Research Journal of Business and Management, 7(9), 1-8. 
Patrick, H., \& Williams, G. C. (2012). Self-determination theory: Its application to health behavior and complementarity with motivational interviewing. International Journal of Behavioral Nutrition and Physical Activity, 9.

Peek, S. T. M., Luijkx, K. G., Rijnaard, M. D., Nieboer, M. E., Van Der Voort, C. S., Aarts, S., Van Hoof, J., Vrijhoef, H. J. M., \& Wouters, E. J. M. (2016). Older adults' reasons for using technology while aging in place. Gerontology, 62(2), 226-237.

Peek, S. T. M., Wouters, E. J. M., van Hoof, J., Luijkx, K. G., Boeije, H. R., \& Vrijhoef, H. J. M. (2014). Factors influencing acceptance of technology for aging in place: A systematic review. International Journal of Medical Informatics, 83(4), 235-248.

Peters, D., Calvo, R. A., \& Ryan, R. M. (2018). Designing for motivation, engagement and wellbeing in digital experience. Frontiers in Psychology, 9.

Pew, R. W., \& Van Hemel, S. B. (2004). Technology for adaptive aging. Washington, DC: The National Academies Press.

Pol, M., Van Nes, F., Van Hartingsveldt, M., Buurman, B., De Rooij, S., \& Kröse, B. (2016). Older people's perspectives regarding the use of sensor monitoring in their home. Gerontologist, 56(3), 485-493.

Porter, C. E., \& Donthu, N. (2006). Using the technology acceptance model to explain how attitudes determine Internet usage: The role of perceived access barriers and demographics. Journal of Business Research, 59(9), 999-1007.

Przybylski, A. K., Rigby, C. S., \& Ryan, R. M. (2010). A motivational model of video game engagement. Review of General Psychology, 14(2), 154-166.

Roca, J. C., \& Gagné, M. (2008). Understanding e-learning continuance intention in the workplace: A selfdetermination theory perspective. Computers in Human Behavior, 24(4), 1585-1604.

Rupp, M. A., Michaelis, J. R., McConnell, D. S., \& Smither, J. A. (2018). The role of individual differences on perceptions of wearable fitness device trust, usability, and motivational impact. Applied Ergonomics, 70, 77-87.

Ryan, R. M., \& Deci, E. L. (2000). Intrinsic and extrinsic motivations: Classic definitions and new directions. Contemporary Educational Psychology, 25(1), 54-67.

Ryan, R., Patrick, H., Deci, E. L., \& Williams, G. C. (2008). Facilitating health behaviour change and its maintenance: Interventions based on self-determination theory. The European Health Psychologist, 10, $2-5$.

Schaper, L. K., \& Pervan, G. P. (2007). ICT and OTs: A model of information and communication technology acceptance and utilisation by occupational therapists. International Journal of Medical Informatics, 76, 212-221.

Schepers, J., \& Wetzels, M. (2007). A meta-analysis of the technology acceptance model: Investigating subjective norm and moderation effects. Information and Management, 44(1), 90-103. 
Schwarzer, R. (2008). Modeling health behavior change: How to predict and modify the adoption and maintenance of health behaviors. Applied Psychology, 57(1), 1-29.

Silveira, P., van het Reve, E. Daniel, F., Casati, F., \& De Bruin, E. D. (2013). Motivating and assisting physical exercise in independently living older adults: A pilot study. International Journal of Medical Informatics, 82(5), 325-334.

Stern, C., Blanchard, D., \& Bourgeois, S. (2014). Respite care for people with dementia and their carers. International Journal of Evidence-Based Healthcare, 12(4), 267-268.

Tacken, M., Marcellini, F., Mollenkopf, H., Ruoppila, I., \& Széman, Z. (2005). Use and acceptance of new technology by older people. Findings of the international MOBILATE survey: "Enhancing Mobility in Later Life". Gerontechnology, 3(3), 126-137.

Taherdoost, H. (2018). A review of technology acceptance and adoption models and theories. In Procedia Manufacturing, 22, 960-967.

Teo, T., \& Lee, C. B. (2010). Explaining the intention to use technology among student teachers: An application of the theory of planned behavior (TPB). Campus-Wide Information Systems, 27(2), 60-67.

Theoharidou, M., Tsalis, N., \& Gritzalis, D. (2016). Smart home solutions: Privacy issues. In J. van Hoof, G. Demiris, \& E. J. M. Wouters (Eds.), Handbook of smart homes, health care and well-being. Berlin: Springer.

Thielke, S., Harniss, M., Thompson, H., Patel, S., Demiris, G., \& Johnson, K. (2012). Maslow's hierarchy of human needs and the adoption of health-related technologies for older adults. Ageing International, $37(4), 470-488$.

Townsend, D., Knoefel, F., \& Goubran, R. (2011). Privacy versus autonomy: A tradeoff model for smart home monitoring technologies. In Proceedings of the Annual International Conference of the IEEE Engineering in Medicine and Biology Society (pp. 4749-4752).

Trepte, S., \& Reinecke, L. (Eds.). (2011). Privacy online: Perspectives on privacy and self-disclosure in the social Web. Berlin: Springer.

Tsai, J. Y., Kelley, P., Drielsma, P., Cranor, L. F., Hong, J., \& Sadeh, N. (2009). Who's viewed you? The impact of feedback in a mobile location sharing application. In Proceedings of the 27th International Conference on Human Factors in Computing Systems.

van Hoof, J., Kort, H. S. M., Rutten, P. G. S., \& Duijnstee, M. S. H. (2011). Ageing-in-place with the use of ambient intelligence technology: Perspectives of older users. International Journal of Medical Informatics, 80(5), 310-331.

Vansteenkiste, M., Lens, W., \& Deci, E. L. (2006). Intrinsic versus extrinsic goal contents in selfdetermination theory: Another look at the quality of academic motivation. Educational Psychologist, 41(1), 19-31.

Venkatesh, V., Morris, M. G., Davis, G. B., \& Davis, F. D. (2003). User acceptance of information technology: Toward a unified view. MIS Quarterly, 27(3), 425-478. 
Venkatesh, V., Speier, C., \& Morris, M. G. (2002). User acceptance enablers in individual decision making about technology: Toward an integrated model. Decision Sciences, 33(2), 297-316.

Wehmeyer, M. L. (1998). Self-determination and individuals with significant disabilities: Examining meanings and misinterpretations. Research and Practice for Persons with Severe Disabilities, 23(1), 5-16.

Westin, A. F. (2003). Social and political dimensions of privacy. Journal of Social Issues, 59(2), 243-261.

Wilkowska, W., \& Ziefle, M. (2012). Privacy and data security in e-health: Requirements from the user's perspective. Health Informatics Journal, 18(3), 191-201.

Williams, G. C., Ryan, R. M., Rodin, G. C., Grolnick, W. S., \& Deci, E. L. (1998). Autonomous regulation and long-term medication adherence in adult outpatients. Health Psychology, 17(3), 269-276.

Yusif, S., Soar, J., \& Hafeez-Baig, A. (2016). Older people, assistive technologies, and the barriers to adoption: A systematic review. International Journal of Medical Informatics, 94, 112-116.

Zhang, S., Zhao, J., \& Tan, W. (2008). Extending TAM for online learning systems: An intrinsic motivation perspective. Tsinghua Science and Technology, 13(3), 312-317.

Ziefle, M., \& Carsten, R. (2010). Acceptance of pervasive healthcare systems: A comparison of different implementation concepts. In Proceedings of the International ICST Conference on Pervasive Computing Technologies for Healthcare. 


\section{Appendix A}

Table A1. A Comparison Table of Features in Fitbit Devices that One can Use to Track Physical Activity

\begin{tabular}{|c|c|c|c|c|c|c|c|c|c|c|c|}
\hline Model & Wearability & Released & Steps & Floor & $\begin{array}{l}\text { Heart } \\
\text { rate }\end{array}$ & Sleep & $\begin{array}{l}\text { Sleep } \\
\text { stages }\end{array}$ & Clock & $\begin{array}{l}\text { Water } \\
\text { resistance }\end{array}$ & $\begin{array}{l}\text { Battery } \\
\text { life }\end{array}$ & $\begin{array}{l}\text { Customi- } \\
\text { zable } \\
\text { appearance }\end{array}$ \\
\hline Classic & $\begin{array}{l}\text { Clipped to } \\
\text { pocket }\end{array}$ & 2009 & $\checkmark$ & $x$ & $x$ & $\checkmark$ & $x$ & $x$ & Resistant & 7 days & $x$ \\
\hline Ultra & $\begin{array}{l}\text { Clipped to } \\
\text { pocket }\end{array}$ & 2011 & $\checkmark$ & $\checkmark$ & $x$ & $\checkmark$ & $x$ & $\checkmark$ & Resistant & 7 days & $x$ \\
\hline One & $\begin{array}{l}\text { Clipped to } \\
\text { pocket }\end{array}$ & 2012 & $\checkmark$ & $\checkmark$ & $x$ & $\checkmark$ & $x$ & $\checkmark$ & Resistant & $\begin{array}{l}10-14 \\
\text { days }\end{array}$ & $\checkmark$ \\
\hline Zip & $\begin{array}{l}\text { Clipped to } \\
\text { pocket }\end{array}$ & 2012 & $\checkmark$ & $x$ & $x$ & $x$ & $x$ & $\checkmark$ & Resistant & $\begin{array}{l}\text { 4-6 } \\
\text { months }\end{array}$ & $\checkmark$ \\
\hline Flex & Wristband & 2013 & $\checkmark$ & $x$ & $x$ & $\checkmark$ & $x$ & $x$ & Resistant & 5 days & $\checkmark$ \\
\hline Force & Wristband & 2013 & $\checkmark$ & $\checkmark$ & $x$ & $\checkmark$ & $x$ & $\checkmark$ & Resistant & $\begin{array}{l}\text { 7-10 } \\
\text { days }\end{array}$ & $x$ \\
\hline Charge & Wristband & 2014 & $\checkmark$ & $\checkmark$ & $x$ & $\checkmark$ & $x$ & $\checkmark$ & Resistant & $\begin{array}{l}\text { 7-10 } \\
\text { days }\end{array}$ & $x$ \\
\hline $\begin{array}{l}\text { Charge } \\
\text { HR }\end{array}$ & Wristband & 2015 & $\checkmark$ & $\checkmark$ & $\checkmark$ & $\checkmark$ & $x$ & $\checkmark$ & Resistant & 5 days & $\checkmark$ \\
\hline Surge & Smartwatch & 2015 & $\checkmark$ & $\checkmark$ & $\checkmark$ & $\checkmark$ & $x$ & $\checkmark$ & Resistant & 7 days & $x$ \\
\hline Blaze & Smartwatch & 2016 & $\checkmark$ & $\checkmark$ & $\checkmark$ & $\checkmark$ & $\checkmark$ & $\checkmark$ & Resistant & 5 days & $\checkmark$ \\
\hline Alta & Wristband & 2016 & $\checkmark$ & $x$ & $x$ & $\checkmark$ & $x$ & $\checkmark$ & Resistant & 5 days & $\checkmark$ \\
\hline Charge 2 & Wristband & 2016 & $\checkmark$ & $\checkmark$ & $\checkmark$ & $\checkmark$ & $\checkmark$ & $\checkmark$ & Resistant & 5 days & $\checkmark$ \\
\hline
\end{tabular}

We mark the device we used in the study with grey. 